\title{
(Des)encontros no hospital: itinerário terapêutico de uma experiência intersexo*
}

\author{
Shirley Acioly Monteiro de Lima** \\ Paula Sandrine Machado ${ }^{* * *}$ \\ Pedro Paulo Gomes Pereira ${ }^{* * * *}$
}

Resumo

Quando uma pessoa intersexo decide reingressar no serviço de saúde para questionar a designação sexual que lhe foi atribuída ao nascimento, ela deve necessariamente percorrer diferentes instâncias e caminhos. Nessa trajetória, entra em contato com distintos profissionais (técnicos, enfermeiras, médicos) e tipos de serviços (secretaria de atendimento, clínicas médicas $e$ laboratórios). Esta etnografia, realizada durante dois anos, permitiu uma aproximação com complexos itinerários e com soluções e dilemas das pessoas intersexo. Com base nesta experiência etnográfica, este texto buscará acompanhar um desses percursos, focalizando o encontro e as relações estabelecidas entre uma pessoa intersexo adulta $e$ os grupos específicos de atendimento. Surgem dessas trajetórias inauditas formas de perceber as práticas médicas e as ações efetuadas no percurso dentro do hospital.

Palavras-chave: Intersexo, Registro Civil, Violência, Serviço de Saúde, Gênero.

\footnotetext{
* Recebido para publicação em 17 de junho de 2016, aceito em 19 de outubro de 2016. Shirley Acioly Monteiro de Lima realizou estudo, concepção e revisão do artigo. Paula Sandrine Machado revisão do artigo e Pedro Paulo Pereira Gomes orientação do estudo, concepção e revisão final do artigo.

** Doutora pelo Programa de Pós-Graduação em Saúde Coletiva da Unifesp, São Paulo, Brasil. shirleyacioly@yahoo.com

*** Professora do Departamento de Psicologia Social e Institucional e do Programa de Pós-Graduação em Antropologia Social da UFRGS, Porto Alegre, RS, Brasil. machadops@gmail.com

**** Professor do Departamento de Medicina Preventiva e do Programa de Pós-Graduação em Saúde Coletiva da Unifesp. pedropaulopereira@hotmail.com
} 
(Dis)Encounters at The Hospital: The Therapeutic Itinerary of an Intersex Person

\begin{abstract}
When an intersex person decides to rejoin the health service in order to question his/her sexual assignment, he/she must necessarily go through different departments. In this trajectory, he/she will interact with different social actors (technicians, nurses, medical doctors) and types of services (secretariat of healthcare, medical clinics and laboratories). This research, developed during two years, allowed us to understand complex itineraries as well as the intersex persons' solutions and hesitations. Based on this ethnographical experience, this paper will follow one of these trajectories. It will focus on the encounter and the relations established by an adult intersex person and the healthcare groups. From these trajectories, unprecedented forms of perceiving the medical and non-medical practices and actions in the itinerary within the hospital will emerge.
\end{abstract}

Keywords: Intersex, Civil Name, Violence, Health Service, Gender. 
Decidir questionar a designação sexual atribuída por ocasião do nascimento é difícil, especialmente quando se trata de uma pessoa intersexo. ${ }^{1}$ Cabe a ela percorrer diferentes instâncias $e$ caminhos, que envolvem serviços de atendimento social, jurídico $e$ biomédico. Nesses percursos, é conduzida a reingressar no sistema de saúde para lidar com a condição intersexual - em alguns casos, descoberta $e$ acompanhada na infância - e entra em contato com distintos atores sociais desses serviços. Para auxiliá-la em suas demandas e no questionamento da designação sexual, esses atores solicitam um laudo ou uma intervenção médica. Esses intrincados trajetos compõem o tema deste trabalho.

Por dois anos desenvolvi uma etnografia com observação participante e acompanhamento cotidiano de pessoas intersexo. Nesse período, atuei em projetos, oficinas, saraus e demais ações promovidas pelo Centro de Referência e Defesa da Diversidade (CRD) da cidade de São Paulo. Além disso, busquei seguir o itinerário $^{2}$ de meus interlocutores em suas idas a hospitais, a instituições judiciárias e mesmo no dia a dia em suas residências.

Nesse processo, acabei por me aproximar de um de meus principais interlocutores, Bahia, nascido em 1989, em uma cidade no interior da Bahia e que, para preservar seu anonimato, escolheu um pseudônimo que fizesse referência à sua origem. No decorrer do trabalho de campo, estabeleci com ele um contato íntimo e duradouro que me possibilitou compreender vários de seus dilemas - similares aos de outras pessoas intersexo com as quais convivi -, se bem que colocados de forma mais clara $e$ intensa do que pelos outros interlocutores que eu já havia acompanhado. Segui Bahia em seu itinerário a partir do momento

\footnotetext{
1 Usarei a denominação "intersexo" (uma variação de intersexualidade) por ser uma categoria autoidentificatória.

2 Entendo "itinerário" como uma cadeia de eventos voltada para o tratamento da aflição e apresentada como um conjunto de planos e ações, movimentos, agenciamentos e concepções que se sucedem, se mesclam ou se sobrepõem em uma interpenetrabilidade de opções (Rabelo; Alves; Souza, 1999; Pinho; Pereira, 2012).
} 
em que decidiu alterar seus documentos e retomar o tratamento iniciado na adolescência.

Meu interlocutor é um rapaz intersexo, adulto, nascido em uma cidade do interior da Bahia e residente na cidade de São Paulo. Apresenta-se com nome social masculino, mas, no registro civil, seu sexo e seu nome são femininos. Percorri o itinerário de Bahia pela cidade de São Paulo, ao longo de vinte meses, compreendidos entre junho de 2012 e fevereiro de 2014. Foram muitas manhãs e tardes de deslocamentos e desafios enfrentados nesse percurso. Narrarei essa experiência neste texto, detendo-me, entretanto, nos atendimentos de saúde, na vivência dos encontros, nas consultas e nos atritos gerados dentro de hospitais. Nesses locais sobrevieram não só acontecimentos marcados pelo controle médico do corpo intersexo, mas também conflitos dentro e fora das equipes médicas, advindos da visível contradição entre sua aparência (masculina) e seu nome de registro (feminino). Houve também tentativas de criação de procedimentos que fugiam ao protocolo estabelecido para o trânsito de Bahia dentro dos espaços hospitalares.

Em 2001, Bahia descobriu sua condição dentro de um hospital pediátrico e, desde então, passou a se reconhecer e a se apresentar como tal. ${ }^{3} \mathrm{O}$ interesse deste trabalho é acompanhar a maneira como meu interlocutor se constrói em seus itinerários, como se percebe e como é delineado um lento processo de desmedicalização ${ }^{4}$ de uma condição que nasce nos contornos da biomedicina. Cabe deixar claro que a aflição de Bahia foi dada pela marca de um olhar médico que classificou seu corpo como ambíguo, o que o levou a um registro civil que não condiz com o que ele imaginava e criava para si. Sua "ambiguidade genital"

3 Devo salientar que os termos médicos serão acionados ao longo do artigo, na medida em que formam parte da trajetória de Bahia, a despeito de eles não capturarem sua experiência.

4 Desmedicalização pressupõe pensar a intersexualidade a partir de atravessamentos múltiplos, que não são restritos ao campo médico, mas buscam alternativas para ele, questionando-o e dando-lhe a possibilidade de se apresentar como é visto. Cf. Gaudenzi \& Ortega (2012). 
produziu outras ambiguidades: não apenas o corpo era discordante de certa masculinidade, mas também seu nome discordava de seu corpo e de seu desejo.

\section{Apresentando Bahia e os hospitais: o reingresso ao Sistema de Saúde}

Ao nascer, Bahia ingressou em uma teia de relações sociais e de significados definidos por sua genitália. Essa parte do corpo, que assume importante papel de marcador da diferença entre os sexos, impôs a construção de gênero e de práticas sexuais que deveriam ser por ele vividas. Bahia, entretanto, rompeu com as expectativas familiares no momento em que foi diagnosticado pela equipe de endocrinologia do Instituto da Criança do Hospital das Clínicas da Faculdade de Medicina da Universidade de São Paulo, como um rapaz intersexo. Apesar dos termos médicos que o definem $e$ ficaram registrados em seu prontuário $e$ encaminhamentos médicos (Distúrbio de Diferenciação Sexual [DDS] e pseudo-hermafrodita masculino por deficiência da enzima 5-alfa redutase), Bahia se apresentou a mim como intersexo. Criado como menina, Bahia conheceu sua condição "intersexual" (nomeada e instituída dentro de um hospital) aos 12 anos. Até aquele momento, tendo aprendido com seus pais que sua genitália era diferente e merecia ser mantida em segredo, ele viveu dúvidas $e$ angústias relacionadas a seu corpo e sua orientação sexual. ${ }^{5}$ Seu corpo não se parecia com o de suas irmãs, pois faltavam-lhe os brotos da mama, e a genitália era, segundo ele, distinta, uma vez que tinha um clitóris maior. Bahia se "sabia" menina, como lhe assegurava a mãe. A revelação sobre o que seria denominado "ambiguidade genital" foi um giro em sua história. Durante a adolescência, passou por acompanhamento médico e psicológico, transitou entre o feminino e o masculino, alternando o uso de roupas e acessórios e circulando entre o

\footnotetext{
${ }^{5}$ No caso de crianças, o ativismo intersexo advoga por uma assignação de sexo que não seja definitiva, caso não se forcem modificações corporais, dando à pessoa a possibilidade de modificar a assignação (e seu corpo) conforme seu desejo.
} 
grupo de meninas e o de meninos em busca de referências. Sem ter realizado qualquer intervenção cirúrgica, firmou-se como homem e assumiu essa nova apresentação social.

No momento em que estava prestes a passar pela primeira cirurgia, aos 18 anos, Bahia abandonou o acompanhamento médico, rompendo assim com a ideia de atenção baseada no pressuposto da inevitabilidade do uso do recurso da tecnologia cirúrgica de "normalização genital" das pessoas intersexo (Kessler, 2002; Chase, 1998). Demonstrou medo de se submeter a um procedimento cirúrgico e ter de fazer uma pausa em sua vida, de abrir mão de seu trabalho (Bahia era pedreiro e recebia por dia trabalhado). Nessa época, ele era arrimo de família, pois seu pai havia falecido e sua mãe se encontrava doente. Afligia-o também realizar uma intervenção cirúrgica para modificar seu corpo sem nunca tê-lo experimentado sexualmente. Postergou então a cirurgia de correção genital, que já havia sido agendada, e a mudança de seus registros civis.

Aos 23 anos, com a vida familiar e financeira mais equilibrada, Bahia estava vivendo uma relação afetivo-sexual havia mais de três anos. Ele e sua companheira apresentavam-se como casados. Após passar por constrangimentos decorrentes do nome feminino em seus documentos, ele decidiu mudar seus registros (certidão de nascimento e carteira de identidade). No Núcleo Especializado do Combate à Discriminação, Racismo e Preconceito da Defensoria Pública do Estado de São Paulo (NCDRP), onde foi buscar auxílio para a troca de documentação, em setembro de 2012, descobriu que seria necessário retornar ao serviço de saúde que o atendera na adolescência para obter um "laudo médico" que confirmasse sua condição, atestasse o "erro no registro inicial" e sustentasse seu pedido (Barros, 1990). Bahia poderia também retomar seu acompanhamento médico, interrompido no início da vida adulta.

Entusiasmado, ele aceitou o encaminhamento para a retomada do tratamento de saúde exatamente no ponto em que 
tinha parado: a realização da cirurgia de "correção genital". ${ }^{6} \mathrm{O}$ instituto pediátrico onde Bahia fora atendido na adolescência, no entanto, não podia mais recebê-lo por já ser ele maior de idade. Dessa forma, o encaminhamento do NCDRP lhe garantiu o agendamento para triagem em um serviço de referência em sexualidade, localizado no Instituto de Psiquiatria da Universidade de São Paulo, dentro do mesmo complexo hospitalar que diagnosticara Bahia.

Sua trajetória seria fortemente marcada por direcionamentos $e$ vivências com interlocutores da biomedicina. Fossem eles médicos ou não, estavam impregnados pela linguagem desse campo de saber. A intersexualidade, entendida como doença, pressupunha o acompanhamento pela psiquiatria, pela endocrinologia e pela urologia. Nessa sequência, as três áreas realizaram o escrutínio da alma e do corpo de Bahia para definir seu lugar social. Assim se deram suas experiências no hospital, sendo encaminhado de uma equipe para outra, até que fosse determinada a conduta médica para seu "tratamento".

Como qualquer paciente, para entrar no hospital Bahia precisava apresentar seu nome e seu documento de identificação. Em seu caso, no entanto, o nome que utilizava - seu nome social - divergia daquele registrado no documento de identidade. Nos casos de intersexualidade, para além das questóes de "investigação" do verdadeiro sexo ou da definição de um sexo viável, existe também um foco de atenção e apreensão na atribuição de um nome ao nascituro (Fraser; Lima, 2012). Em situações de diagnóstico precoce, todo procedimento de assignação sexual tende a ser realizado o quanto antes para que se registrem nome e sexo na certidão de nascimento. Entretanto, quando o processo investigativo ocorre após o registro de nascimento e há discordância entre o nome e o sexo adotados

\footnotetext{
${ }^{6}$ Maffia \& Cabral (2003:87) discutem a ética de uma intervenção cirúrgica que considere os princípios de autonomia e identidade do sujeito em contraposição à prática recorrente na qual a cirurgia é utilizada como instrumento normativo de correção corporal e de adequação do sujeito às normas sociais.
} 
pela pessoa, além da "ambiguidade" genital, há também a ambivalência de documentos. É nesse entre-lugar que se encontrava Bahia.

As análises sobre a tensão estabelecida entre os usos do nome social $e$ do nome de registro têm sido realizadas no atendimento a travestis e transexuais pelo sistema de saúde (Bento, 2006; Teixeira; Rocha; Rasera, 2012). Ao ingressar em hospitais e ambulatórios para tratamento de saúde, terapias hormonais ou para cirurgia de redesignação sexual, as pessoas atendidas requerem o uso do nome social - pelo qual se identificam e se reconhecem - em detrimento do nome de registro.

Quando investigava o reingresso de adultos intersexo no sistema de saúde para questionar a assignação atribuída, encontrei estudos que, apesar de tratar de pessoas intersexo que realizaram mudança de sexo social (e intervenção cirúrgica), não abordaram os conflitos vividos dentro do hospital (Inácio, 2010; Morando, 2012). Os demais estudos nacionais sobre pessoas intersexo no sistema de saúde tiveram como foco o gerenciamento sociomédico e cotidiano da intersexualidade, as representações e práticas sociais acionadas nas decisões que envolviam a designação do sexo em crianças intersexo (Machado, 2008), o desenvolvimento psicossexual, a concordância com a assignação sexual realizada na infância (Santos, 2006), bem como as estratégias de enfrentamento para lidar com a estigmatização decorrente da ambiguidade genital (Canguçú-Campinho, 2008). Nenhum estudo, entretanto, se deteve nos conflitos vividos diretamente por adultos intersexo que questionavam a definição médica dentro do hospital, espaço no qual este estudo se insere.

Segundo Teixeira, Rocha \& Rasera (2012), nos serviços de saúde há despreparo e falta de estrutura para atender os usuários (travestis e transexuais) que apresentam demanda de uso do nome social. Ainda que a Portaria $\mathrm{n}^{\circ} 1.820$, de 13 de agosto de 2009, que dispõe sobre os direitos e deveres dos usuários da saúde, estabeleça o direito ao uso do nome de preferência - independentemente do nome no registro civil -, a não inclusão de espaço para o nome social em documentos, formulários e protocolos oriundos da esfera 
federal gera constrangimentos e dificuldades nos encaminhamentos dos usuários dentro e fora do serviço.

No caso de Bahia, ao colocar em primeiro plano a pessoa intersexo que contesta a assignação de sexo e o nome atribuído na infância, percebi situações inusitadas no tratamento recebido em seu itinerário dentro do hospital. É a partir desse ponto que ele e eu retornamos à recepção - a porta de entrada ao serviço de saúde na situação analisada - do Serviço de Sexualidade. Ali ele iniciou sua interação com os distintos atores sociais que o receberiam na retomada a seu atendimento médico para a correção cirúrgica de sua genitália, considerada dentro das definições médicas como "incompletamente formada".

\section{De volta à porta de entrada}

No final de outubro de 2012, estávamos diante do Instituto de Psiquiatria, na região central da cidade de São Paulo. Bahia, que havia procurado orientação jurídica para a troca de nome em seus registros civis, fora encaminhado para uma consulta médica no Serviço de Sexualidade. Ao cruzar a porta do imponente edifício e apresentar o agendamento da consulta, seguranças indicaram ao jovem rapaz a secretaria de atendimento, localizada no mesmo andar térreo. Bahia acomodou-se em uma cadeira na recepção e aguardou até ser chamado pela recepcionista. Como parte do processo de cadastro do usuário, após entregar o ofício com agendamento da consulta, ele teve seu documento de identificação solicitado e apresentou seu Registro Geral (RG). Ao receber o documento em suas mãos, a funcionária examinou detidamente a foto, o nome e, sem esconder surpresa, exclamou: "Oxe, que esquisito! Quem é o paciente?". Ante a confirmação de Bahia, ela voltou seu olhar para o monitor do computador $e$ perguntou: "É Bahia, né? Deixa só eu confirmar alguns dados aqui, Bahia, porque tá Bahiana!". Ele sorriu e afirmou: "Mas eu acho que é isso mesmo". A atendente confirmou: "É isso mesmo? 
Tá bom". Ao verificar uma passagem anterior em outro instituto daquele complexo hospitalar, ela pediu desculpas e perguntou se ele desejava registrar seu nome social. Bahia sorriu e concordou. Da impressora, saíram etiquetas, com o nome social, que foram afixadas pela recepcionista à ficha de atendimento. Depois desse pequeno, mas dramático episódio, Bahia foi autorizado a dirigir-se ao andar superior.

Chegando ao local informado, ele procurou a recepção do Serviço de Sexualidade e foi em busca da secretária que, em conversa direta com a assistente social do NCDRP, havia feito seu agendamento. Apresentou-se e entregou os documentos fornecidos pela assistente social. Ao ler o nome impresso no ofício $e$ na ficha gerada na recepção do edifício e confrontá-los com o nome do RG, a secretária olhou para ele e disse: 'É assim seu nome e nome social? Esse ambulatório seria de transexualismo, só que transexualismo a gente não tá marcando!”. Em pé, em frente ao balcão de atendimento, separado da secretária apenas por um vidro, Bahia, atônito, ouviu - assim como todos ali presentes - sua explanação acerca das "doenças ou disfunções" que os atendidos deveriam apresentar para consulta naquele serviço. Além do constrangimento a que ele foi submetido pela forma como sua questão fora publicamente divulgada, intrigou-me também, naquele momento, o conteúdo. A questão não é criticar o uso desses termos patológicos pela secretária, mas indagar como um setor que deveria cuidar de transexuais utilizava termos como "transexualismo" e "disfunção" para referir-se às pessoas atendidas. As palavras e os termos contêm uma carga importante, bem sabemos; seu uso em um hospital - local onde as pessoas buscam acolhida para suas aflições - não pareceu adequado, como Bahia me fez perceber. As palavras melindraram-no e, ao evocar doença, performatizaram uma violência logo na entrada do dispositivo que proclamava atuar para elidir ou amenizar as aflições.

Constrangido ao ser interpelado, Bahia, na tentativa de realizar naquele dia a consulta marcada, fez uso das palavras da secretária para se explicar: "Então, o meu caso é, assim, uma 
disfunção; o que aconteceu é...". Ela o interrompeu bruscamente e o repreendeu: "Ah, disfunção? E você tem um nome social?". Bahia tentou prosseguir: "Ahn, [minha questão é] endocrinológica!". A secretária voltou-se para mim, que o acompanhava, e atestou: "Então, aqui não tem, aqui não é endócrino. O caso dele é de transexualismo, é para o ambulatório de transexualismo. Eu posso estar marcando você na lista de espera e você aguarda. Não é o caso desse atendimento hoje".

Bahia, sem jeito, exclamou: "Entendi". A secretária, centrando-se na questão do nome, se justificou: "Aqui, quem tem nome social, a gente considera, atende como transexual. Todo mundo que vem com nome social é transexual, no nosso entender". Não bastasse a admoestação a Bahia, a secretária telefonou para o NCDRP para desfazer o que ela considerava "um erro de agendamento", pois já havia comunicado a todos os centros de referenciamento que estavam sem agenda para atendimentos a transexuais. Na presença de Bahia e dos demais pacientes na recepção, ela iniciou uma conversa telefônica com a assistente social.

Terminada a ligação na qual a secretária deixou claro que não seria prestado atendimento naquele dia, Bahia, quase sem esperanças, sussurrou para a ela: "É assim. Não é nem transexualidade, nem o outro probleminha que você falou. Eu sou um intersexo!". A secretária voltou a ler o ofício, que não fazia menção alguma à sua condição ou ao motivo da avaliação. Percebendo sua hesitação, ele recuperou sua confiança $e$ prosseguiu, agora com voz mais firme: "Você não está entendendo, eu sou um intersexo!". A secretária, menos imperativa, perguntou:

Você é hermafrodita? É isso? Hermafrodismo? Então, hermafrodismo a gente deixa só o seu nome, porque aí o médico vai ver qual é o caso. A gente deixa, por enquanto, o seu nome [de registro]. Aí o médico que coloca, se você tem o nome social, tá? 
Estava evidente que a autoidentificação de Bahia não seria acatada naquele espaço até que o médico o avaliasse e proferisse o veredito. Então, dadas as "explicações", a secretária substituiu o nome social pelo nome civil e gerou novas etiquetas para afixar na ficha de atendimento.

Bahia ficou visivelmente abalado. Tendo "descoberto" sua condição de intersexo num hospital quando jovem, não imaginou que poderia passar por tal situação de constrangimento justamente com aqueles que supostamente deveriam entender sua variação corporal $e$ as questões relacionadas a seu nome. Não dentro de um hospital! Tivera de lutar para afirmar-se como menino dentro da escola; conseguira, com seus 18 anos, ser contratado para trabalhar em uma função "masculina" com, inclusive, carteira de trabalho assinada; fora expulso de uma loja e escoltado por seguranças, por portar documento com nome feminino; fora impedido de retirar a segunda via de seu registro de identidade até provar que aquele documento realmente lhe pertencia. Nesse flashback, não entendia como ninguém conseguia compreender sua situação, precisamente na fase que, para ele, já era de finalização de seu processo, já nas portas do hospital. Logo em sua chegada, Bahia confrontou-se com uma secretária, a quem pediu autorização para entrar e teve de aguardar até que ela decidisse acatar o agendamento.

$\mathrm{O}$ reingresso ao atendimento mostrou a Bahia que, diferentemente do tratamento recebido na infância, ele teria de se apresentar e de se defender sozinho, pois não contava com a proteção da mãe ou com a complacência dos atendentes. Afinal, ainda que tivesse uma aparência masculina, o nome no RG denunciava que havia algo "errado", e ele percebeu, agora com mais intensidade, a dureza e o rechaço no serviço de saúde diante do que é considerado como ambiguidade (Machado, 2008). À medida que ingressava no hospital, Bahia compreendia que não dispunha da "coerência necessária" (Pino, 2007) entre seu corpo e seu nome, o que o expunha de forma problemática.

$\mathrm{Na}$ sala de espera, percebi que o olhar de Bahia vagava pelo espaço daquele lugar insólito. Certamente as palavras da 
secretária ainda ecoavam em sua mente. Quando tentava se acalmar, um grito interrompeu sua espera: seu nome feminino atravessara o salão. Em um sobressalto, ele se adiantou em direção ao consultório antes que os outros pacientes o notassem. Dentro da cumplicidade estabelecida ao longo de nosso convívio, me foi dado por Bahia o status de acompanhante e meu acesso aos locais por ele percorridos deveu-se à sua autorização pessoal, assim eu o acompanhei. Bahia entregou a ficha ao médico, que examinou o material e, olhando para ele e para mim, perguntou: "Quem é a Bahiana?". Bahia se apresentou e o médico prosseguiu: "O nome social é Bahiana mesmo?". "Não, meu nome social é Bahia". "Tá, é que daí eu poderia ter chamado pelo nome correto se tivesse avisado à secretária", justificou o médico. Ele me olhou sem jeito, pois havia avisado à secretária.

Ansioso por contar sua história e obter ajuda em sua troca de nome, Bahia teve, antes, de percorrer o roteiro de investigação conduzido pelo médico. Ao perceber que Bahia se apresentava como intersexo, quase como buscando um atalho, a atenção do médico se voltou para o cariótipo: "Você sabe se você é XX ou se você é XY?". Após anos de atendimento entre a infância e adolescência, Bahia guardava consigo anotações médicas daquela época. Do material que tinha em mãos, ele sacou um pedido de consulta do serviço de pediatria, do ano de 2007, e entregou ao médico. Após examinar o material, o médico exclamou: "É XY! Você é homem! Biologicamente, você é homem, tá? A sua genética é igual à minha!". ${ }^{7}$

Antes de prosseguir, peço que o leitor imagine, por um momento, essa assunção, enunciada pelo médico, agora na boca de Bahia: "Nós somos iguais!". Tal afirmação seria tomada por estranha e poderia causar recusa ou rejeição. Afinal, é a biomedicina quem define os diagnósticos e ao médico é dado o

${ }^{7}$ Margriet van Heesch (2009) chama a atenção para cuidados com o diagnóstico, avaliação física e até mesmo informação sobre cromossomos sexuais no momento em que o médico investiga casos de intersexualidade. Sobre o manejo médico acerca da determinação do sexo de um indivíduo e mudança de sexo, ver Stefan Hischauer (1998). 
poder de se dizer igual, não o contrário. Então, pela segunda vez no Instituto de Psiquiatria (com a secretária e agora com o médico), coube a Bahia acatar o que lhe era dito. A cena da entrada, com a violência inicial vivida em seu reingresso, ficou marcada como se fosse uma memória envenenada (Das, 2007) e o acompanhou até o final de sua trajetória no hospital.

O médico prosseguiu em voz alta: "deficiência de 5-alfa redutase, cariótipo $46 \mathrm{XY}$, opção sexo masculino". Terminada a leitura, voltou-se para Bahia e explicou a "diferença de uma enzima que não consegue produzir o hormônio masculino em quantidade adequada", ou seja, a origem orgânica de seu "problema". A partir daquele momento, a consulta então seguiu o rumo que Bahia desejava desde o início: sua apresentação como homem apesar de seu registro de nascimento e de sua criação, na infância, como menina. Com base nos registros prévios e na entrevista com Bahia, o médico, ao final do atendimento, concluiu:
É, Bahia, o teu caso, na verdade, não é pra cá, neste prédio aqui. Porque aqui vêm pessoas com problemas psicológicos, por exemplo, uma pessoa que tem uma genitália normal, o pênis normal, testículo, tudo, mas quer se transformar em mulher. Ou uma mulher normal e tal, que quer se transformar em homem, isso por um aspecto psicológico. Teu caso é um aspecto físico, um aspecto orgânico. O melhor grupo para acompanhar é o grupo do hospital de endocrinologia.

Com a informação de que "não tinha problemas psicológicos e por isso aquele não seria lugar para seu atendimento", Bahia despediu-se do psiquiatra do Serviço de Sexualidade. Tal afirmação reassegurou o que ele já sabia e lhe trouxe alívio, pois Bahia não precisaria retomar o atendimento psicológico realizado na adolescência. Na ficha de encaminhamento para a endocrinologia, notou uma discreta correção em seu nome e uma anotação: "DDS". Como explicou o médico, ele tinha Distúrbio do Desenvolvimento Sexual, o que se baseava na premissa de que o sexo e a enunciação do nome vinham acompanhados da hipótese diagnóstica. Ou seja, 
o diagnóstico se convertia em uma espécie de evidência da natureza que permitia o acesso ao direito a um nome.

\section{O encontro com os "especialistas em intersexualidade"}

No Serviço de Sexualidade, Bahia saiu do domínio da psiquiatria para o da endocrinologia. No mesmo dia, cruzou o complexo hospitalar e dirigiu-se a uma pequena e movimentada recepção por onde tinha circulado na adolescência. Entregou o encaminhamento que tinha em mãos $e$ teve sua consulta agendada para quatro dias depois.

Retornamos à consulta na endocrinologia, no dia $e$ no horário marcados. Às oito horas da manhã, Bahia retirou uma senha no guichê de atendimento e foi orientado a aguardar até que seu número fosse indicado no painel luminoso. Lá pelas 11 horas da manhã, o painel indicou a senha e o número da sala para a qual deveria se encaminhar. Já era final de outubro de 2012 quando Bahia formalmente retomava o atendimento médico por ele interrompido aos 18 anos.

Logo em sua chegada, três médicas o notaram $e$ questionaram a razão de ter sido referenciado pelo serviço de psiquiatria. Bahia, após explicar sua passagem pela Defensoria Pública e o direcionamento para o Serviço de Sexualidade, afirmou: "Sou um hermafrodita, como o pessoal diz! Um intersexo. (...) Meu nome era Bahiana, só que eu tinha partes íntimas que não decorreria do nome Bahiana”. Esse era o entendimento que ele tinha da intersexualidade, uma não correlação entre a genitália e seu nome. E, assim, apresentou-se à equipe que o acompanharia nos meses seguintes, mostrando-se ciente da sua condição intersexo e também de como os outros se referiam a ele, hermafrodita.

Ao longo das três consultas que se deram nas semanas subsequentes, todos os aspectos da vida e do tratamento pregresso de Bahia foram averiguados. Tudo foi perguntado, num escrutínio que parecia ser infinito: da infância à vida adulta, das brincadeiras à vida sexual, da escola ao ingresso no mercado de 
trabalho. Na história de Bahia, seu corpo não apenas o diferenciava de suas irmãs e irmãos como também o distanciava de seus interesses e brincadeiras. Ele não se encaixava no que era esperado para uma "menina" e tampouco tinha atributos que o definissem como "menino". Era excluído tanto dos espaços femininos quanto dos masculinos. A revelação de sua condição intersexual, ocorrida aos 12 anos de idade dentro daquele complexo hospitalar, abriu-lhe um novo jeito de estar no mundo $e$, em busca de um lugar de reconhecimento, ele transitara entre o feminino e o masculino (o lugar por ele desejado). Quando a virilização de seu corpo, que havia sido bloqueada pela deficiência enzimática, pôs-se em marcha, aos 16 anos, Bahia já se apresentava como menino. Sem o uso de medicamentos ou próteses, vivenciou seu corpo e sua (in)completude, descobrindo os prazeres $e$ os medos que sua diferença corporal the proporcionavam.

Diante de sua história, do diagnóstico inicial e do relato de uma "sexualidade estabilizada" (ele vivia uma relação heterossexual há mais de três anos), Bahia, que aos 18 anos de idade "fugira" da realização da cirurgia, garantia aos médicos desejar a construção de uma genitália masculina. Diferentemente da consulta no Instituto de Psiquiatria, na qual descreveu sua genitália a partir das perguntas do médico, na endocrinologia, foi realizado o exame clínico após a anamnese. O corpo de Bahia foi olhado, tocado, medido. Eu acompanhei todos os movimentos de escrutínio e percebia sua expressão de dor e desconforto. Enquanto a equipe da endocrinologia buscava taxas hormonais, cariótipo e outros exames prévios de Bahia, a urologista, que acompanhava o atendimento, centrava sua atenção na correção genital.

Desse momento em diante, Bahia passou a ser cuidado, concomitantemente, pelas equipes de endocrinologia e de urologia, detentoras de saberes que garantiriam sua avaliação de saúde e a determinação da técnica cirúrgica a ser realizada em sua construção genital. No território dos especialistas, seu cariótipo $e$ seu diagnóstico da deficiência enzimática, assim como a presença 
de testículos internos, foram confirmados por exames. Já não havia dúvidas para equipe médica de que ele se tratava de um "homem biológico" (Bahia e não Bahiana, como em seu registro de nascimento). E, conforme seu desejo, o nome do documento deveria ser corrigido, bem como sua genitália tida como "incompleta". Cabe salientar que esse escrutínio do corpo ao qual fora submetido em nada diferiu dos exames anteriores, quando fora levado ao Instituto Pediátrico por sua mãe. Bahia já sabia o que os médicos agora confirmavam.

Cumpridas as consultas, ele recebeu informações detalhadas sobre o procedimento cirúrgico a ser conduzido pela urologia, devendo realizar os exames solicitados e aguardar a convocação, pois, "sendo intersexo, ele era uma das prioridades", como afirmou uma das médicas da endocrinologia. Apesar das certezas acerca dos encaminhamentos biomédicos, a equipe deixou transparecer uma dúvida: haveria a necessidade de direcioná-lo à seção de psicologia? Ainda que os médicos concordassem que "o atendimento não seria para definição", dada a segurança de Bahia e da equipe sobre a realização da cirurgia, o encaminhamento foi realizado. Ele então apresentou-se à psicóloga responsável pelo atendimento a pessoas intersexo $e$ transexuais acompanhadas pela equipe da endocrinologia. E esse foi o único atendimento que não pude acompanhar, a pedido da profissional.

Ao sair do consultório, Bahia me viu sentada esperando o término da consulta, comentou que a psicóloga, que o atendeu algumas vezes na adolescência durante sua primeira passagem pelo hospital, em um único encontro de menos de 30 minutos, o "diagnosticou" com princípio de depressão. Inconformado com o diagnóstico baseado em testes, Bahia perguntou a ela se o acompanhamento psicológico era necessário para a realização da cirurgia. Ao ser informado sobre a não obrigatoriedade - pois "aos 23 anos ele já sabia o que queria" -, Bahia abriu mão do atendimento. Na porta do consultório, ele encerrou o que viria a ser a primeira e a última consulta. Ainda que a psicóloga continuasse enviando e-mails e formulários nas semanas 
seguintes, Bahia não os respondeu. Comentou comigo: "Mesmo se fosse por causa do tratamento, eu não ia aceitar. (...) ia ser mais uma dúvida pra mim e eu não queria dúvida. Eu já sei o que eu quero". Bem diferente de quando bem jovem, Bahia não mais necessitava ser tutelado e buscava relacionar-se com os serviços de saúde diretamente.

\section{A realização de exames e o contato com técnicos do hospital}

Nos meses de novembro e dezembro de 2012, Bahia continuou seu périplo para a realização de exames pré-cirúrgicos. A cada novo exame ou consulta entrava em contato com funcionários de diferentes áreas do hospital. Enfim, seu corpo foi "trazido à existência" (enact) numa multiplicidade de práticas (Mol, 2003). Todavia, em toda apresentação e entrega de documentação, percebia o impacto que a discordância entre sua imagem e seu nome causava. No serviço de radiologia, ao ler o nome feminino no formulário entregue por Bahia, a atendente forneceu as orientações sobre o preparo para o exame, dirigindose a mim, que o acompanhava. $O$ não questionamento sobre quem seria Bahiana e nossa cumplicidade o salvaram de um temido constrangimento como o vivido no Instituto de Psiquiatria. No dia do exame, entretanto, foi necessária a conferência de seu documento de identidade e, para seu alívio, mesmo após uma segunda olhada para Bahia, o atendente manteve o evento restrito, acompanhando-o à sala de exame sem alardear a descoberta sobre o nome de registro civil daquele rapaz.

Em outra ocasião, no setor de coleta de sangue, após entregar a solicitação de exame no balcão de atendimento, o funcionário que o recebeu, instantes depois de ler seu nome, o chamou de volta. De forma diversa das outras pessoas, Bahia foi orientado a entregar o material nas mãos do funcionário que organizava a coleta, evitando assim que seu nome fosse chamado em viva voz e, consequentemente, notado pelos demais presentes, pacientes ou funcionários. Dessa fila, Bahia foi conduzido para a técnica de enfermagem que o atendera. Nos minutos em que se 
manteve sob os cuidados da técnica, conversaram. Ela, no entanto, ao verificar a etiqueta com o nome Bahiana, surpreendeu-se e contou a ele que, naquela mesma manhã, havia atendido "uma mulher de 75 anos, hermafrodita, que não tinha nada de homem, mas ela 'tinha os dois'... tinha a deficiência também". Bahia ouviu a história e, educadamente, limitou-se a comentar que seu caso era apenas um problema no RG. Em sua estratégia de preservação, ele não alongou a conversa nem apresentou à técnica elementos que falassem de si (apenas mencionou os problemas com o documento de identidade) $e$ confirmassem o diagnóstico que ela, por comparação, estendia a ele.

Pelas recepções de atendimento, filas, consultórios, salas de exame, Bahia passaria despercebido não fosse pelo nome feminino. Indicado na etiqueta afixada nos formulários, seu nome de registro insistia em evidenciar a discordância entre sexo $e$ gênero. E esse era sempre motivo de apreensão em cada retorno ao hospital, pois, todas as vezes, recebia um tratamento distinto. Nesse itinerário, a incerteza quanto às formas de cuidado que lhe eram dispensadas, a insegurança sobre sua nomeação, as idas $e$ vindas em especialidades que pareciam não se conciliar, a curiosidade latente em profissionais de saúde ávidos pelo exótico, acabaram por deixar Bahia entre apreensivo e cansado, a ponto de por vezes pensar em desistir.

\section{"Agora você vai nascer menino, Bahia!"}

Pouco mais de três meses após seu retorno ao hospital, confirmando a prioridade atestada por uma das médicas, Bahia recebeu convocação para a primeira cirurgia. No dia marcado, em janeiro de 2013, ele se encaminhou à enfermaria da endocrinologia. A enfermeira que o atendeu lhe entregou a guia de internação na qual, para a surpresa de Bahia, estava registrado seu nome social masculino. Orgulhoso, Bahia seguiu para o setor de internação, onde deveria formalizar os trâmites de ingresso. Com sua internação autorizada, cartões de visita e etiquetas para 
afixar em seu prontuário, Bahia se reapresentou à enfermaria. Mal havia sido acomodado no quarto e recebido a pulseira de identificação, Bahia foi chamado no corredor: "Seu nome pode gerar confusão", explicou a enfermeira-chefe. A intensa circulação de profissionais de distintas equipes de saúde exigia que ele retornasse ao setor de internação para corrigir seu nome, alegou a enfermeira. Diante da reação de perplexidade de Bahia, a enfermeira o reencaminhou ao quarto $e$ se ausentou por uns instantes. Retornou, minutos depois, com nova pulseira de identificação. Agora havia a indicação "(Bahia) Bahiana”, nome social e de registro lado a lado. Era notório que algo acontecia com o nome, como se fosse necessário construir uma ambiguidade para que ele pudesse ser objeto de cuidados num hospital.

Durante a internação, os profissionais que travavam contato com Bahia e verificavam "seus nomes" no prontuário e na pulseira enfrentavam dúvidas sobre como se dirigir a ele uma vez que a indicação "(Bahia) Bahiana" denunciava a presença do feminino que não percebiam à primeira vista. As enfermeiras, que se tornaram mais próximas e o acompanhavam diariamente, comentaram que os casos que chegavam à enfermaria eram "de homens que queriam virar mulher" (transexuais) e se espantaram ao saber que ele "queria sair como homem", o que fazia de Bahia, na linguagem das enfermeiras, "um hermafrodita que foi fazer a cirurgia para ficar só com um sexo".

A alternância de nomes nos registros médicos de Bahia voltou a acontecer dentro do hospital. No dia de sua cirurgia, enquanto eu aguardava sua saída do centro cirúrgico, dirigi-me à enfermeira do setor para obter informações. Dei seu nome social para que fosse consultado na lista de pacientes. A enfermeira, não encontrando seu nome, perguntou: "Bahiana?". Na listagem do centro cirúrgico, o nome social havia desaparecido e constava apenas o nome de registro civil seguido do motivo da intervenção cirúrgica. Assim, comprovando o vínculo indissolúvel entre identidade e forma genital (Maffia; Cabral, 2003:91), era Bahiana quem estava na sala de cirurgia para realizar, conforme especificado 
naquela listagem, "modificação duradoura à personalidade não especificada". ${ }^{8}$ Sabendo tratar-se de uma cirurgia realizada pela urologia, como registrado no material que tinha em mãos, a enfermeira, estranhando a descrição, completou: "Deve ser algo demorado!".

Após a intervenção que durou toda a manhã, Bahia saiu do centro cirúrgico acompanhado por outra enfermeira, que conduzia sua maca. Ao verificar o número do quarto para onde deveria levá-lo, deparou-se com o nome Bahiana e perguntou: "Está errado aqui?". A companheira de Bahia, que estava ao meu lado, respondeu: "Você achou?". A enfermeira, meio constrangida, defendeu-se: "A gente tem alguns casos aqui isolados de mudança de sexo. Então a gente fica confusa com o nome, como é que a gente chama a pessoa. Não estou falando o seu caso, não sei qual o seu caso, enfim...". A imagem de Bahia apresentava-se como um enigma e intrigava cada profissional da equipe de saúde, pois aquele rapaz franzino em nada lembrava uma mulher.

No dia seguinte ao da cirurgia, Bahia recebeu em seu quarto a equipe médica. De acordo com o cirurgião-chefe da urologia, os objetivos definidos para essa cirurgia haviam sido atingidos, $e$ a genitália de Bahia já assumia aspectos "mais masculinizados". Era, coincidentemente, dia de seu aniversário, data propícia para que os profissionais se lembrassem do prometido em uma das primeiras consultas com o cirurgião-chefe da urologia: ele iria "nascer de novo e, agora, menino!". De certa forma, como sugere Anne Fausto-Sterling (2000), as técnicas cirúrgicas em torno das genitálias ajudam a manter o sistema binário de gênero.

Bahia voltou ao hospital outras vezes mais para consultas, exames $e$ outras duas cirurgias que se realizaram entre fevereiro $e$ novembro de 2014. Já conhecido pelas equipes médica e não médica, conseguiu contornar os percalços de seu registro civil

8 A presença de Bahia no hospital seguia um protocolo patologizante. Ainda que os médicos tivessem dito que seu "problema" não era psicológico, ele foi classificado na categoria F 62.9, CID 10 (Classificação Internacional de Doenças), grupo de Transtornos da Personalidade e do Comportamento do Adulto, Capítulo V - Transtornos Mentais e Comportamentais. 
ainda não modificado, contando com a camaradagem dos profissionais que o chamavam por Bahia e registravam seu nome social, apesar de ele não haver feito qualquer solicitação formal ao hospital. Isso, no entanto, não evitava a cobrança pela mudança de seus registros civis, pois, como disseram os médicos, a parte mais importante, a correção de seu corpo, havia sido realizada. As mudanças corporais foram as mais urgentes para Bahia. A correção nos documentos civis já era outra história. O envolvimento com o judiciário não foi menos difícil e doloroso. No entanto, essa outra história não será narrada neste artigo.

\section{Percalços no itinerário de Bahia}

Ao ingressar no serviço de saúde para retomar o tratamento médico, Bahia percorreu distintos setores e clínicas do hospital até a realização da cirurgia de correção genital. Seu primeiro contato na recepção do Instituto de Psiquiatria lhe ensinou que, como adulto, cabia-lhe apresentar seu documento de identificação $e$ informar sobre a divergência entre seu nome e sua imagem. A primeira recepcionista, acostumada a receber pessoas que se dirigiam a diferentes especialidades daquele instituto, seguindo o protocolo de atendimento nos serviços de saúde, ofereceu à Bahia a possibilidade de ser tratado pelo nome com o qual se reconhecia. Uma vez dentro da psiquiatria, no entanto, o Serviço de Sexualidade, segunda etapa de seu itinerário de saúde, trouxelhe uma situação corriqueira fora do domínio da saúde, mas que, apesar de protocolos e decisões sobre o assunto, continuava a existir dentro do hospital: o constrangimento a partir da revelação de seu nome (Greenberg, 2012). A secretária do serviço especializado, habituada à demanda do setor e treinada pelos médicos, buscou explicações e classificações para enquadrá-lo, pois, "se tinha nome social, era transexual".

$\mathrm{O}$ documento de identidade foi o símbolo que despertou a atenção sobre a discrepância de sua identidade e quebrou uma imagem, até então coerente, de sua masculinidade. Bahia se descobriu o "desacreditável" (Goffman, 1963), aquele cuja 
característica distintiva não era (re)conhecida pelos presentes, nem imediatamente percebida. Contudo, ao apresentar seu RG, fora delatado. Seu nome passava a ser algo que merecia a classificação dos profissionais envolvidos, como indicava a ação da secretária em rotular Bahia de transexual. Tal violência o teria detido já na porta do hospital se não fossem sua insistência e sua paciência, que também são formas de agir e atuar (Das, 2007).

Os profissionais de saúde, os funcionários do hospital com os quais Banhia interagia, tentavam, o tempo todo, eliminar a "ambiguidade" que nele percebiam. Esses profissionais encenavam (Mol, 2003) de modo a condenar ou elidir aqueles elementos que produziram um efeito de mistura ou descaracterização na imagem (masculina) de Bahia, fosse o ofício do NCDRP ou o RG. A cena da entrada - a violência inicial vivida em seu reingresso - o acompanhou até o final de sua trajetória no hospital. O saber médico, invocado pela secretária para falar do "transexualismo" de Bahia, traduz a visão - compartilhada pelo médico da triagem - de que o serviço atende a pessoas que vivem um conflito entre corpo $e$ subjetividade. Como se vê, o caráter patologizante está problematizado na linguagem que assume uma forma de violência quando Bahia, que se identifica como homem, é chamado publicamente pelo nome que o posiciona no feminino. Dentro do Serviço de Sexualidade, localizado no Instituto de Psiquiatria, a medicina conserva a legitimidade social de falar sobre os corpos, de defini-los e caracterizá-los como normais ou patológicos (Canguilhem, 2011).

Não sendo um transexual, Bahia deveria colocar-se como portador de uma disfunção para ser atendido naquele serviço. Mas, como manifestou a secretária, que disfunção apresenta nome social senão a transexualidade? A explicação veio do médico que, ao se deparar com uma anotação em um registro médico de Bahia, constatou que ele "tinha um problema orgânico e não psicológico" e, portanto, aquele instituto não era lugar para seu atendimento. Ao percebê-lo como "igual" pela presença de cariótipo XY e apresentação social masculina, o médico psiquiatra teve reassegurada a ordem e reconheceu em Bahia um "homem 
como ele". Indicou então os caminhos para eliminação da ambiguidade que o tornariam normal, por meio da restauração de seu corpo masculino.

Nas idas e vindas de seus itinerários nos serviços de saúde, Bahia ingressou no domínio dos especialistas em intersexualidade e, a partir daquele momento, iniciou o processo para a cirurgia. Bahia, cuja condição orgânica o colocou em suspenso, poderia, com a intervenção biomédica, escrever em seu corpo a marca do masculino que lhe faltava, tornando possível a predicação pública do gênero (Cabral, 2006:78) em seus registros civis.

A forma híbrida produzida no contexto da "sexualidade ininteligível" constituiu o não lugar de Bahia, uma vida cujo reconhecimento demonstrava ser precário ou mesmo evasivo (Butler, 2003). O Distúrbio de Desenvolvimento Sexual explicava o espaço a ele alocado, mas não justificava sua manutenção nesse local, uma vez que, ao tomar conhecimento de sua condição, criou seu próprio espaço e sua definição de masculino.

A força da história de Bahia reside sobretudo em sua resistência. Caso tivesse acatado sua socialização $e$ se transformado na menina que desde o nascimento fora assim nomeada - ou mesmo realizado a genitoplastia masculinizante antes de ter iniciado sua vida sexual -, ele não teria experienciado os conflitos que the asseguraram a possibilidade de viver seu corpo, experimentar os espaços sociais e definir onde e como desejaria transitar. Ele chegou à idade adulta com o peso da diferença corporal (a "ambiguidade genital" tal como definida pelos padrões médicos) que se transformou em uma ambiguidade em diversas esferas do social, inclusive em seu Registro de Identidade Civil (Bahia/Bahiana). E foi a partir de suas escolhas $e$ de seus processos de negociação que ele buscou ferramentas sociomédicas para tirá-lo desse entre-lugar.

A relação com os médicos, o convívio dentro do hospital e a decisão de se afastar do atendimento e de retornar tantos anos depois - em suma, o aprendizado sobre sua condição e seu corpo - foram vivenciados por ele de maneira distinta de tantos casos de criança intersexo (Cabral; Benzur, 2005; Cabral, 2006; Kessler, 2002; 
Dreger, 2000; Machado, 2008; Preves, 2002). Bahia contou com o fator "tempo", crucial em matéria de assignação sexual (Preciado, 2002), e retornou ao sistema de saúde já adulto e diretamente responsável pelas decisões referentes a seu corpo, permitindo-lhe então uma negociação (dolorosa e com muitas contradições) com a biomedicina e seu aparato tecnológico. A história de Bahia parece sugerir que os serviços de saúde necessitam de identidades objetificadas e consubstanciadas, reforçando e mesmo criando identidades para poder trabalhar $e$, assim, atender os pacientes.

Dentro do hospital, ao insistir em se apresentar como Bahia, e não Bahiana, como está em seu RG e no prontuário médico, ele ignorou as fronteiras, questionou a norma e desenhou seu próprio itinerário terapêutico. Em cada um dos atos de escolha (não tomar hormônio feminino aos 12 anos, não realizar a cirurgia masculinizante aos 18 anos ou rejeitar o atendimento psicológico aos 23 anos), ele definiu e negociou qual seria o tratamento adequado para sua aflição. Bahia, ao decidir pela construção da genitália masculina "padrão", buscou sair da situação de "ilegibilidade do excepcional" (Cabral, 2006). Falta-lhe ainda, porém, apagar a "ambiguidade" por meio da troca de seu nome juridicamente. Enquanto não o fizer, seguirá com os registros médicos no feminino, e o tratamento que lhe será oferecido estará baseado na "leitura e interpretação" que cada ator e cada instância farão de sua condição. $\mathrm{O}$ nome feminino, se não for modificado, será mantido como rastro da ambiguidade, como memória do corpo inconforme.

No itinerário percorrido com Bahia, a biomedicina não é um aglomerado único; dentro do hospital, residem diferenças nos hábitos, nas técnicas e no manejo dos corpos. Enquanto a medicina parece unificada pelo saber acerca da intersexualidade $e$ define como atender e evocar Bahia, médicos e demais atores sociais não o estão, como pude perceber no decorrer da etnografia. A máquina do hospital não é homogênea, pois suas diversas instâncias nem sempre funcionam de forma coerente $e$ coesa. O sofrimento e o incômodo de Bahia no hospital, bem como sua trajetória, desenham movimentos nos quais os serviços 
de saúde, as diversas instâncias de um hospital, buscam classificar e capturar Bahia como (e apenas como) intersexo. Ele, no entanto, consegue reinventar-se continuamente, valendo-se das mesmas instâncias que poderiam tê-lo capturado.

\section{Notas finais}

Bahia nos interpela de diversas maneiras. Uma história complexa permeada por violências no percurso. Nos seus itinerários, longe de vivenciar o hospital como uma estrutura rígida e coesa, percebo as multiplicidades de visões e práticas ${ }^{9}$ nas estruturas clínicas e administrativas que se manifestam nas tensões $e$ alternâncias entre o seguimento do protocolo de atendimento $e$ o desvio de procedimentos. Diversos fatores interagem: anatomia, fisiologia, bioquímica, patologia, insegurança, pressão, emoções, prazos e regras, a que estão submetidos os atores envolvidos médicos e não médicos - nos cuidados à saúde (Mol; Berger, 1994).

A história de Bahia deixa claro também que a máquina hospitalar parece necessitar de identidades objetificadas $e$ consubstanciadas para poder atuar. Assim, reforça e mesmo cria identidades para poder trabalhar $e$ atender os "pacientes" que muitas vezes não se enquadram nas definições biomédicas. $\mathrm{O}$ périplo de Bahia nos hospitais mostra, entretanto, que é possível encontrar novos caminhos e desvios de negociar com essa linguagem objetificadora.

A experiência etnográfica desafia a noção do hospital como um dispositivo homogêneo que atua sobre os corpos das pessoas intersexo, mostrando os conflitos entre os microcosmos, as formas de tratamento diferenciadas $e$ as distintas maneiras de a biomedicina operar (Mol; Berger, 1998). O hospital (ou a biomedicina) não é um dispositivo homogêneo. É certo que atua numa gramática heteronormativa, mas há fissuras e espaços não

\footnotetext{
9 As práticas orientadas ao manejo da intersexualidade são ditadas por uma ciência comprometida em localizar, teorizar e promover a diferença sexual como a verdade do corpo (Machado, 2012).
} 
rastreados que Bahia parece perceber e tentar percorrer. $\mathrm{Na}$ história de Bahia, o hospital, com suas variadas instâncias, se apresenta como um lugar instável. Ali há uma busca de reapropriação das tecnologias que os hospitais possibilitam. Os corpos inconformes procuram os hospitais $e$ as técnicas biomédicas de modo a não só reinventar os instrumentos simbólicos e materiais que constroem o masculino e o feminino, mas também a redesenhar a gramática de gênero-tecnologia.

Dessa forma, Bahia não é alguém exclusivamente vinculado às malhas do dispositivo que tudo controla e passivo diante do poder médico-hospitalar. Antes, ele age de diversas maneiras, ora acata decisões médicas, ora evita discussões ou opta por não participar, ora elege as pessoas com quem deve compartilhar sua história (ou parte dela), trilhando caminhos inauditos nessas ações.

Para encerrar, devo dizer que aprendi com Bahia a maneira como determinados atores não se encaixam naquilo que geralmente se imagina como "agência" (Das, 2007). Por exemplo, noções como paciência e resiliência - demonstradas por todo périplo pelo qual passou - são mais vinculadas à passividade do que à resistência. Bahia, entretanto, abala os modelos preestabelecidos de resistência ou, pelo menos, apresenta outras possibilidades de pensá-los, mostrando que existem outras formas de lidar com a exclusão e com os processos de abjeção que se distanciam dos modelos de resistência heroica.

\section{Referências bibliográficas}

Alves, Paulo César; RABelo, Míriam Cristina; SouzA, Iara Maria. Escolha e avaliação de tratamento para problemas de saúde: considerações sobre o itinerário terapêutico. In: RABELO, M.C.; ALVES, P.C.B.; SouZA, I.M.A. (orgs.). Experiência de doença e narrativa. Rio de Janeiro, Fiocruz, 1999, pp.125-138.

BARROS, I. G. Intersexualidade: retificação de registro civil: quesitos da curadoria de familia. Justitia (52), São Paulo, 1990, pp.12-20. 
BENTO, Berenice. O dispositivo da transexualidade no contexto hospitalar. In: CÁCERES, Carlos F.; PISCITELli, Adriana; CAREAGA, Gloria; FRASCA, Tim (orgs.). Sexualidad, estigma y derechos humanos:desafios para el acceso a la salud em America Latina. Lima, UPCH, 2006, pp.177-205.

BUTLER, Judith. O parentesco é sempre tido como heterossexual? cadernos pagu (21), Campinas-SP, Núcleo de Estudos de GêneroPagu/Unicamp, 2003, pp.219-226.

CABRAl, Mauro; BenzUR, Gabriel. Cuando digo intersex: un dialogo introductorio a la intersexualidad. cadernos pagu (24), Campinas-SP, Núcleo de Estudos de Gênero-Pagu/Unicamp, 2005, pp.283-304.

CABRAL, Mauro. En estado de excepción: intersexualidad e intervenciones sociomédicas. In: CÁCERES, Carlos F.; PISCITELLI, Adriana; CAREAGA, Gloria; FRASCA, Tim (orgs.). Sexualidad, estigma y derechos humanos:desafios para el acceso a la salud em America Latina. Lima, UPCH, 2006, pp.69-90.

CANGUÇÚ-CAMPINHO, Ana Karina. Aspectos da construção da maternidade em mulheres com filhos intersexuais. Dissertação (Mestrado em Saúde Comunitária), Instituto de Saúde Coletiva, Universidade Federal da Bahia, 2008.

CANGUILHEM. Georges. O normal e o patológico. Rio de Janeiro, Forense Universitária, 2011.

CHASE, Cheryl. Until five years ago, intersexuals remained silent. In: FEINBERG, Leslie. Trans liberation: beyond pink and blue... Nova Iorque, Beacon Press, 1998, pp.88-93.

DAS, Veena. Life and words: violence and the descent into the ordinary. Berkeley, University of California Press, 2007.

DREGER, Alice. Hermafrodites and the medical invention of sex. Londres, Harvard University Press, 2000.

FAUSTO-STERLING, Anne. Sexing the body: gender politics and the constructions of sexuality. Nova Iorque, Basic Books, 2000.

FRASER, Roberta Tourinho Dantas; LIMA, Isabel Maria Sampaio Oliveira. Intersexualidade e direito à identidade: uma discussão sobre o assentamento civil de crianças intersexuadas. Journal of Human Growth and Development (22) , São Paulo, 2012, pp.358-366. 
GAUDENZI, Paula.; ORTEGA, Francisco. O estatuto da medicalização e as interpretações de Ivan Illich e Michel Foucault como ferramentas conceituais para o estudo da desmedicalização. Interface: Comunicação, Saúde, Educação (16), Botucatu, 2012, pp.21-34.

GOFFMAN, Erving. Estigma: notas sobre a manipulação da identidade deteriorada. Rio de Janeiro, LTC, 1963.

GREENBERG, Julie.A. Intersexuality and the law: why sex matters. Nova Iorque e Londres, New York University Press, 2012.

HEESCH, Margriet van. Do I have XY chromosomes? In: HolmES, Morgan (org.). Critical intersex (Queer interventions). Londres, Ashgate Publishing, 2009, pp.123-145.

HISCHAUER, Stefan. Performing sexes and genders in medical practices. In: Mol, Annemarie; BERGER, Marc (org.). Differences in medicine: unravelling practices, techniques and bodies. Durham, Duke University Press, 1998, pp.13-27.

INÁCIO, Marlene. Aspectos psicossociais e sexuais de pacientes com distúrbios do desenvolvimento sexual a longo prazo. Tese (Doutorado em Medicina), Universidade de São Paulo, 2010.

KESSLER, Suzane. Lessons from the intersexed. New Brunswick, Nova Jersey e Londres, Rutgers University Press, 2002.

MACHADO, Paula Sandrine. Intersexualidade, intersexualidades: notas sobre alguns desafios teóricos, metodológicos e políticos contemporâneos. In: MISKOLCI, Richard; PELÚCIO, Larissa (orgs.). Discursos fora da ordem:sexualidades, saberes e direitos. São Paulo, Annablume, Fapesp, 2012. (Coleção Queer).

MACHADO, Paula Sandrine. O sexo dos anjos: representações e práticas em torno do gerenciamento sociomédico e cotidiano da intersexualidade. Tese (Doutorado em Antropologia Social), Universidade Federal do Rio Grande do Sul, 2008.

MAFFIA, Diana; CABRAL, Mauro. Los sexos son o se hacen? In: MAFFIA, Diana (org.). Sexualidades migrantes: género y transgéneros. Buenos Aires, Feminaria, 2003.

Mol, Annemarie; Berger, Marc. Principles and practices of medicine. Culture, Medicine and Psychiatry (18), junho 1994, pp.247-265. 
Mol, Annemarie; Berger, Marc. Differences in Medicine: unravelling practices, techniques and bodies. Durham, Duke University Press, 1998.

Mol, Annemarie. The Body Multiple: Ontology in Medical Practice. Durham, N.C., Duke University Press, 2003.

MORANDO, Luis. Miloca que virou David: intersexualidade em Belo Horizonte (1917-1939). Revista Bagoas (8), 2012, pp.147-169.

PINHO, Paula; PEREIRA, Pedro Paulo Gomes. Itinerários terapêuticos: trajetórias entrecruzadas na busca por cuidados. Interface: Comunicação, Saúde, Educação (16), 2012, pp.435-447.

PINO, Nádia Perez. A teoria queer e os intersexo: experiências invisíveis de corpos des-feitos. cadernos pagu (28), Campinas-SP, Núcleo de Estudos de Gênero-Pagu/Unicamp, 2007, pp.149-174.

PORTARIA $\mathrm{n}^{\circ} 1.820$, de 13 de agosto de 2009. Dispõe sobre os direitos e deveres dos usuários da saúde. [http://conselho.saude.gov.br/ultimas_noticias/2009/01_set_carta.pdf]

PRECIADO, Beatriz. Manifiesto contra-sexual. Madri, Pensamiento Opera Prima, 2002.

PREVES, Sharon. Sexing the intersexed: an analysis of sociocultural responses to intersexuality. Signs (27), 2002, pp.523-556.

SANTOS, Moara. Desenvolvimento da identidade de gênero em casos de intersexualidade: contribuições da psicologia. Tese (Doutorado em Psicologia), Universidade de Brasília, 2006.

TeIXEIRA, Flavia do Bonsucesso; RochA, Rita Martins Godoy; RASERA, Emerson Fernando. Construindo saberes e compartilhando desafios na clínica da travestilidade. In: MISKOLCI, Richard; PELÚCIO, Larissa (org.). Discursos fora da ordem: sexualidades, saberes e direitos. São Paulo, Annablume, Fapesp, 2012, pp.155-178. 